\title{
Özofagogastrik Bileșke Kanserleri ve Cerrahi Tedavisi
}

\author{
Esophagogastric Junction Carcinoma and Surgical Treatment
}

Gökhan Kocaman'1, Serkan Enön ${ }^{1}$

Ankara Universitesi Tıp Fakültesi Göğüs Cerrahisi AD

\begin{abstract}
Proksimal mide ve özofagogastrik bileșke (ÖGB) adenokarsinomu sıklığı özellikle batı dünyasında artma eğilimindedir. 1998 yılında özofagogastrik bileșke adenokarsinomları için Siewert sınıflaması yayınlandı. Sınıflama esas olarak tümörün topografik özelliklerine dayanır. AJCC'nin 7. Kanser Evreleme Kılavuzu'nda özofagogastrik bileșke kanserleri ve bileșkeye ya da distal özofagusa uzanan $5 \mathrm{~cm}$ 'lik proksimal gastrik kanserleri de özofagus kanseri sınıflamasına dahil edilmektedir. Tip 1 tümörlerde en sık lenfatik yayılım paraözofagiyal, üst abdominal lenf nodlarına olur. Tip II ve III tümörlerde mediastinal lenf nodu metastazı görülme sıklığı tip I tümörlere göre daha düșük olup, ileri evre hastalarda görülebilir. Genel durumu iyi, uzak metastazı olmayan, Rezektabl ÖGB adenokarsinomlarında en iyi tedavi cerrahidir. Seçilecek cerrahi yöntem konusunda, tip I tümörler için transtorasik fundektomi ve subtotal özofajektomi (İvor Lewis operasyonu), tip III tümörler için D2 diseksiyonla genișletilmiș gastrektomi yapılması konusunda literatürde, geniș ölçüde fikir birliği olduğu gözükmektedir. Yayınlanan çalıșmalar ıșığında tip II tümörler için eğer hiatustan tümörün proksimal uzanımı RO çıkarılabilecekse genișletilmiș gastrektomi yapılması, R0 rezeksiyon yapılamıyacaksa abdominal-sağ transtorasik yaklașımla ( İvor Lewis operasyonu) rezeksiyon uygulanması uygun gözükmektedir. Submukozal tümörlerde endoksopik tedavi yöntemleri uygulanabilir.

Anahtar Sözcükler: Özofagogastrik Bileşke, Adenokanser, Cerrahi Tedavi

Proximal gastric and esophagogastric junction adenocarcinomas (EGJA) are arising in especially western world. In 1998 Siewert published his classification for EGJA which is based on tumors tophography. The 7th edition of AJCC Cancer Staging Manuel includes staging of esophagus and esophagogastric junction cancer also the first $5 \mathrm{~cm}$ of the stomach cancer that invades the esophagogastric junction. For type I tumors the most frequent lymphatic spread is through the paraesophageal and upper abdominal lymph nodes. For type II and type III tumors mediastinal lymphatic invasion frequency is lower. The best treatment for RO resectable EGJA without metastases is surgery. It is widely accepted that for type I tumors Iwor Lewis operation, for type III tumors transabdominal total gastrectomy with D2 lymph node dissection are the best treatment. For type II tumors if RO resection is possible via transabdominal approach, total gastrectomy is appopriate. If RO resection is not possible with this way, transabdominal and transthorasic esophagectomy should be done with two field lymphadenectomy. Endoscopic resection can be done for submucoal tumors.

Key Words: Esophagogastric Junction, Adenocarcinoma, SurgicalManagement
\end{abstract}

Proksimal mide ve özofagogastrik bileşke (ÖGB) adenokarsinomu siklığ1 özellikle batı dünyasında artma eğilimindedir (1-5). Gelişmiş ülkelerde üst gis tümörleri epidemiyolojisinde kayma yaşanmaktadır. Özofagus ve distal mide tümörleri sıklığı azalırken distal özofagus, özofagogastrik bileşke ve kardiya tümörleri sıklı̆̆1 artmaktadır (6). Bu durum batı ülkelerinde artan obezite, artan gastroözofagiyal reflü hastalı̆̆1 ve azalan Helikobakter pilori infeksiyon oranı ile açıklanmaktadır (7-10). Bileşke tümörlerinin tanımı, sınıflamas1, etiyolojisi, evrelemesi ve cerrahi tedavi yaklaşımı konusunda literatürde farklı görüşler bulunmaktadır. 1998 y1lında özofagogastrik bileșke adenokarsinomları için Siewert sınıflaması yayınlandı (Şekil 1). Sınıflama esas olarak tümörün topografik özelliklerine dayanır (11).

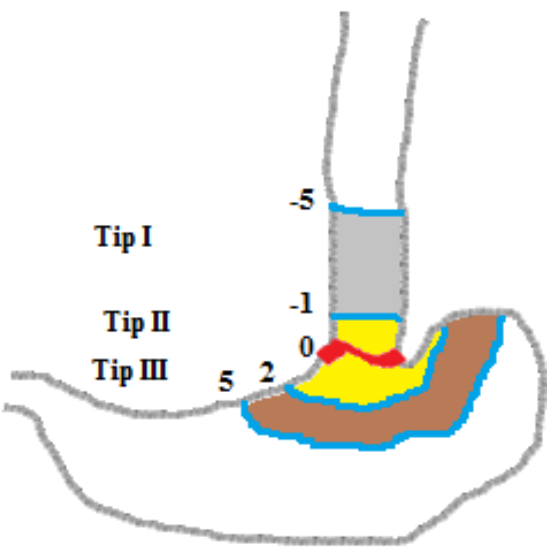

Şekil 1: ÖGB kanseri Siewert sınıflaması 
Tip I: Gastroözofagiyal bileşkenin 1-5 cm üzerinde tümör merkezi olan distal özofagus adenokarsinomlarıdır. Genelde özofagus distalindeki intestinal metaplazi (Barrett özofagus) alanlarından köken alır.

Tip II: Kardiyanın gerçek karsinomu. Kardiyak epitel veya kısa segment intestinal metaplaziden köken alan tümör merkezinin gastroözofagiyal bileşkenin $1 \mathrm{~cm}$ üstü ve $2 \mathrm{~cm}$ altında olduğu gastrik kardiya adenokarsinomlarıdır.

Tip III: Tümör merkezinin gastroözofagiyal bileşkenin $2-5 \mathrm{~cm}$ altında olduğu bileşkeyi ve distal özofagusu aşağıdan infiltre eden subkardiyak gastrik karsinomlarıdır.

Büyük tümörlerde tümör kitlesinin baskın yerleşimi esas alınır. Özellikle tip I ve III tümörler arasında epidemiyoloji, etiyoloji, tümör biyolojisi, lenfatik yayılım açısından farklılıklar bulunmaktadır. Rezeke edilen tip 2 tümörlerin $\% 25$ 'inde Barrett mukoza segmentleri izlenirken, \% 75'inde tipik gastrik kardiya kanseri özellikleri görülür. Bu nedenle en azından cerrahi açıdan tip II ve III tümörler birlikte değerlendirilebilir (12).

\section{Evreleme}

American Joint Committee On Cancer (AJCC)'nin 7. Kanser Evreleme Kilavuz'unda ilk kez özofagogastrik bileşke kanserleri ayrı bir antite olarak değerlendirilmiştir (Şekil 2). Önceki evrelemede bu bölge tümörleri özofagus ve mide sınıflaması kullanılarak değerlendirilmekteydi. Bu da farklı evrelemelere yol açmaktaydı. Yedinci evreleme sistemi özofagus kanserleri ile birlikte özofagogastrik bileşke kanserleri ve bileşkeye ya da distal özofagusa uzanan 5 cm'lik proksimal gastrik kanserleri de özofagus kanseri sinıflamasina dahil etmektedir (13). Yapılan diğer değişiklikler: İ situ tümör (Tis) tekrar tanımlandı ve T4 alt sinıflara ayrıldı, bölgesel lenf nodları tekrar tanımland, $\mathrm{N}$ metastaz içeren lenf nodu sayısına göre alt s1niflara ayrıldı, M tekrar tanımlandı, skuamöz hücreli karsinom ve adenokarsinom için ayrı evrelendirme grupları oluşturuldu, evre gruplamaları T, N, M ve $G$ sinıfları kullanılarak tekrar belirlendi şeklinde özetlenebilir (Tablo 1-5).

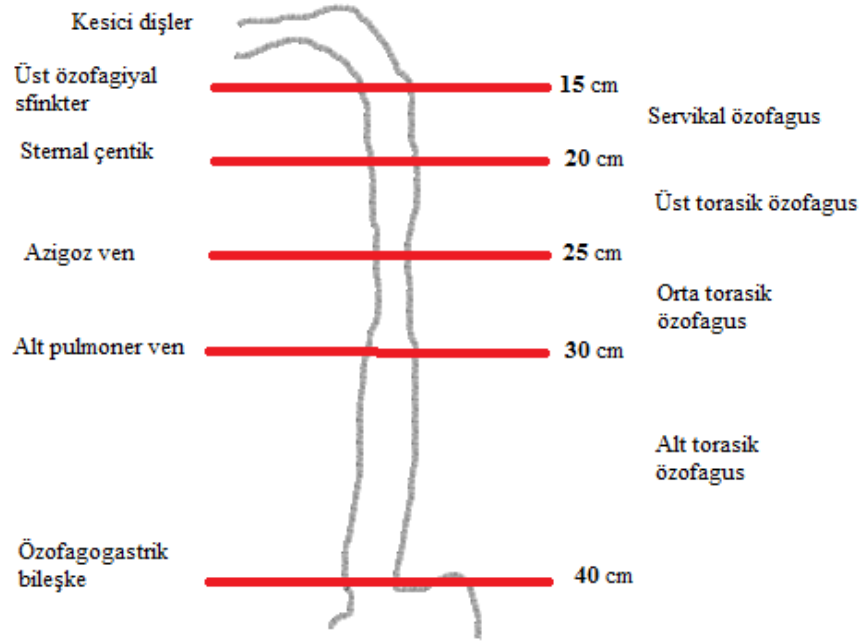

Şekil 2: Özofagus kanseri yerleşim yeri sınıflaması

Tablo 1: Anatomik belirleyicilerdeki değişiklikler

\begin{tabular}{|l|l|l|}
\hline T sınıflaması & N sınıflaması & M sınıflaması \\
\hline $\begin{array}{l}\text { Tis yeniden tanımlandıve T4 alt } \\
\text { gruplara ayrıldı }\end{array}$ & Bölgesel lenf nodu yeniden tanımlandı & $\begin{array}{l}\text { M yeniden } \\
\text { tanımlandı }\end{array}$ \\
\hline Tis yüksek dereceli displazi & $\begin{array}{l}\text { Boyundan çölyak lenf nodlarına kadar } \\
\text { bütün periözofagiyal lenf nodları }\end{array}$ & $\begin{array}{l}\text { M0 uzak } \\
\text { metastaz yok }\end{array}$ \\
\hline $\begin{array}{l}\text { T4a plevra, perikard, diyafram } \\
\text { invazyonu gösteren rezektabl tümör }\end{array}$ & N altgrupları yeniden tanımlandı & $\begin{array}{l}\text { M1 uzak } \\
\text { metastaz var }\end{array}$ \\
\hline $\begin{array}{l}\text { T4b aorta, vertebra, trakea } \\
\text { invazyonu gösteren unrezektabı } \\
\text { tümör }\end{array}$ & N0 bölgesel lenf nodu metastazı yok & \\
\hline & N1 1-2 pozitif bölgesel lenf nodu & \\
\hline & N2 3-6 pozitif bölgesel lenf nodu & \\
\hline & N3 $\geq 7$ pozitif bölgesel lenf nodu & \\
\hline
\end{tabular}

Tablo 2: Anatomik olmayan belirleyicilerdeki değişiklikler

\begin{tabular}{|l|l|l|}
\hline $\begin{array}{c}\text { Histopatolojik } \\
\text { hücre tipi }\end{array}$ & \multicolumn{1}{|c|}{ Histolojik derece } & \multicolumn{1}{c|}{ Kanser lokalizasyonu } \\
\hline Adenokarsinom & G1 iyi diferansiye & Üst torasik kesicilerden $20-25 \mathrm{~cm}$ sonrası \\
\hline $\begin{array}{l}\text { Yassı hücreli } \\
\text { karsinom }\end{array}$ & G2 orta diferansiye & Orta torasik kesicilerden $25-30 \mathrm{~cm}$ sonrası \\
\hline & G3 kötü diferansiye & Alt torasik kesicilerden $30-40 \mathrm{~cm}$ sonrası \\
\hline \multicolumn{2}{|l|}{ G4 diferansiye olmayan } & \\
\hline $\begin{array}{l}\text { Özofagogastrik bileșke; tümör merkezi alt torasik özofagus, bileșke veya midenin } 5 \mathrm{~cm} \text { lik } \\
\text { proksimal kısmında yer alan ve bileșkeyi veya distal torasik özofagusu invaze eden kanserlerdir }\end{array}$ \\
\hline
\end{tabular}

Tablo 3: Adenokarsinom yeni TNM evrelemesi

\begin{tabular}{l|l|l|l|l}
\hline Evre & T & N & M & Derece \\
\hline 0 & Tis (HGD) & N0 & M0 & $1, X$ \\
\hline IA & T1 & N0 & M0 & $1-2, X$ \\
\hline IB & T1 & N0 & M0 & 3 \\
\hline IIA & T2 & N0 & M0 & $1-2, X$ \\
\hline IIB & T2 & N0 & M0 & 3 \\
\hline & T3 & N0 & M0 & Herhangi \\
\hline IIIA & T1-2 & N1 & M0 & Herhangi \\
\hline & T1-2 & N2 & M0 & Herhangi \\
\hline IIIB & T3 & N1 & M0 & Herhangi \\
\hline IIIC & T4a & N0 & M0 & Herhangi \\
\hline & T3 & N2 & M0 & Herhangi \\
\hline & T4a & N1-2 & M0 & Herhangi \\
\hline IV & T4b & Herhangi & MO & Herhangi \\
\hline & Herhangi & N3 & M0 & Herhangi \\
\hline
\end{tabular}




\section{Lenfatik Yayılım ve Lenfadenektomi}

Komplet rezeksiyon gerçekleștirebilmek için tümör yerleşim yerine göre olası lenfatik yayılım yollarını bilmek gerekir. Tip I tümörlerde en sık lenfatik yayılım paraözofagiyal ve üst abdominal lenf nodlarına olur. Ancak \%15'e varan oranlarda karina seviyesine uzanan proksimal mediastinal lenf nodu metastazı da izlenebilir (14). Parry ve ark.'nın (15) 2015 yılında yayınlanan çalışmalarında tip I tümörler için üst mediastinal (paratrakeal, aortikopulmoner, subkarinal) lenf nodu metastaz oran $1 \% 25$ iken, tip II tümörlerde $\% 11$ olarak verilmiştir (p:0,02). Proksimal tümör uzanımı ile üst mediastinal lenf nodu metastazı ilişkili görünmektedir (16). Nunobe ve ark.'nın (17) çalışmalarında özofagiyal uzanım $2 \mathrm{~cm}$ 'nin üzerinde ise \%17.8, 2 cm'nin altında ise $\% 2.2$ inferior mediastinal lenf nodu tutulumu izlenmiştir. Mine ve ark.'nın (18) 142 özofagogastrik bileşke ve alt uç özofagus yassı hücreli karsinom hastasını içeren çalışmalarında diyaframın vena kava inferior açıklığı seviyesine kadar proksimal tümör uzanımı izlenmeyen hastalarda, izlenenlere göre anlamlı derecede daha düşük oranda proksimal ve orta mediastinal lenf nodu metastazı izlenmiştir (\%0-\%5,9 / \%36,4-\%37,8 sirasiyla adeno ca ve yassı hücreli ca için).

Tip II ve III tümörlerde mediastinal lenf nodu metastazı görülme sıklı̆̆1 tip I tümörlere göre daha düşük olup, ileri evre hastalarda görülebilir (19). Buna rağmen çeşitli yayınlarda tip II tümörler için \% 4.7-26.4, tip III tümörler için \%0-15,3 gibi değișik oranlarda mediastinal lenf nodu metastaz oranları verilmiştir (20-22). Çalışmalar arasında küçük farklılıklar olmakla beraber tip II ve III tümörlerde en sık tutulan lenf nodu istasyonları sırasıyla sağ parakardiyal, küçük kurvatur, sol parakardiyal, sol gartrik arter kökü, proksimal splenik arter kökü ve çölyak arter lenf nodlarıdır. Sonrasında tip II tümörler için alt mediastinal, tip III tümörler için büyük kurvatur lenf nodları gelmektedir (23-27). Ayrıca perigastrik lenf nodları için undiferansiye tümörlerin diferansiye tümörlere göre daha sık metastaz yaptığı da bilinmektedir (16). Pedrazzani ve ark. (28) çalışmalarında T2, T3, T4 tümörlerde 6'dan fazla lenf nodu metastazı saptanma oraninı sirasiyla $\% 29, \% 45$ ve $\% 75$ olarak bulmuşlardır. Bu bulgu tümör invazyon derinliği ile lenf nodu metastazı arasındaki ilişkiyi göstermektedir. Yeni evrelemede metastatik lenf nodu sayısının önemine vurgu yapilmakla beraber metastatik lenf nodu oranının (metastatik lenf nodu sayı/çıkarılan lenf nodu sayısı) da prognoz açısından önemli olduğunu bildiren yayınlar mevcuttur. 0.2'den büyük değerler kötü prognostik faktör olarak kabul edilmektedir (29).

Tip I tümörler için özofagus kanseri gibi kabul ederek subkarinal, sağ paratrakeal, üst mediastinal, arkus aorta üst sınırına kadar sol trakeobronşiyal lenf nodlarını içeren mediastinal ve üst abdominal lenf nodu diseksiyonu yapilması önerilmektedir (30). Kurokawa

Tablo 4: T belirleyicileri

\begin{tabular}{|l|l|}
\hline TX & Primer tümör değerlendirilemiyor \\
\hline T0 & Primer tümör bulgusu yok \\
\hline Tis & Yüksek derece displazi \\
\hline T1 & Lamina propria, muskularis mukoza veya submukozayı tutan tümör \\
\hline T1a & Lamina propria veya muskularis mukozayı tutan tümör \\
\hline T1b & Submukozayı tutan tümör \\
\hline T2 & Muskularis propriyayı tutan tümör \\
\hline T3 & Adventisyayı tutan tümör \\
\hline T4 & Komșu yapıları tutan tümör \\
\hline T4a & Plevra, perikard veya diaframı tutan rezektabl tümör \\
\hline T4b & Aorta, vertebra korpusu, trakea gibi diğer komșu yapıları tutan unrezektabl tümör \\
\hline
\end{tabular}

Tablo 5: Özofagiyal lenf nodları isimlendirilmesi ve yerleşim yerleri (AJCC 2012)

\begin{tabular}{|l|l|l|}
\hline $\begin{array}{l}\text { LAP } \\
\text { istasyon no }\end{array}$ & \multicolumn{1}{|c|}{ LAP istasyon isim } & \multicolumn{1}{c|}{ Yerleșim yeri } \\
\hline 1 & $\begin{array}{l}\text { Supraklavikuler lenf } \\
\text { nodları }\end{array}$ & Suprasternal çentik ve klavikulaların üstünde \\
\hline $2 \mathrm{R}$ & Sağ üst paratrakeal nodlar & $\begin{array}{l}\text { İnnominate arter ve trakea kesișme sınırının kaudal } \\
\text { sınırı ve akciğer apeksi arasında }\end{array}$ \\
\hline $2 \mathrm{~L}$ & Sol üst paratrakeal nodlar & Arkus aorta üst ucuyla akciğer apeksi arasında \\
\hline $3 \mathrm{p}$ & $\begin{array}{l}\text { Posterior mediastinal } \\
\text { nodlar }\end{array}$ & $\begin{array}{l}\text { Trakea bifurkasyonunun üstünde paraözofageal } \\
\text { nodlar }\end{array}$ \\
\hline $4 \mathrm{R}$ & Sağ alt paratrakeal & $\begin{array}{l}\text { İnominate arter ile trakea kesișiminin alt ucu ile } \\
\text { azigoz venin sefalik sınırı arasında }\end{array}$ \\
\hline $4 \mathrm{~L}$ & Sol alt paratrakeal nodlar & Arkus aorta üst ucu ile karina arasında \\
\hline 5 & Aortopulmoner nodlar & $\begin{array}{l}\text { Ligamentum arteriozumun lateralindeki subaortik } \\
\text { ve paraaortik } \\
\text { nodlar }\end{array}$ \\
\hline 6 & Ön mediastinal nodlar & Asendan aorta veya innominate arterin üstünde \\
\hline 7 & Subkarinal nodlar & Trakeal karinanın kaudalinde \\
\hline $8 \mathrm{~m}$ & Orta paraözofagieal nodlar & $\begin{array}{l}\text { Trakeal bifurkasyondan inferior pulmoner venin } \\
\text { kaudal sınırına kadar }\end{array}$ \\
\hline $8 \mathrm{I}$ & $\begin{array}{l}\text { Alt paraözofagieal lenf } \\
\text { nodları }\end{array}$ & $\begin{array}{l}\text { İnferior pulmoner venin kaudal sınıından } \\
\text { özofagogastrik bileșkeye kadar }\end{array}$ \\
\hline 9 & Pulmoner ligaman nodları & İnferior pulmoner ligamanın içinde \\
\hline $10 \mathrm{R}$ & Sağ trakeobronșiyal nodlar & $\begin{array}{l}\text { Azigoz venin sefalik sınırından sağ üst lob } \\
\text { bronșunun bașlangıcına kadar }\end{array}$ \\
\hline $10 \mathrm{~L}$ & Sol trakeobronșiyal nodlar & Karina ile sol üst lob bronșu arasında \\
\hline 15 & Diyafragmatik nodlar & $\begin{array}{l}\text { Diyafragma kubbesi ve kururisi yakını veya } \\
\text { arkasında uzanan }\end{array}$ \\
\hline 16 & Parakardiyal nodlar & Gastroözofageal bileșkenin hemen komșuluğunda \\
\hline 17 & Sol gastrik nodlar & Sol gastrik arter boyunca \\
\hline 18 & Splenik nodlar & Ana hepatik arter boyunca \\
\hline 18 Çlyak nodlar & Splenik arter boyunca \\
\hline Çölyak arter kökünde \\
\hline 19 numaralı istasyonlarbölgesel lenf nodları olarak kabul edilmemektedirler \\
\hline
\end{tabular}


ve ark.'nın (31) 2015 yılında yayınlanan çalışmalarına göre proksimal tümör uzanımı ile bileşke arasındaki mesafe $3 \mathrm{~cm}$ 'den büyükse transtorasik yolla yapılacak lenfadenektomi sağkalım avantajı sağlamaktadır. Bileșke tümörlerinde servikal lenf nodu tutulum oranının düşük olması, tutulum olan hastalarda sağkalımın kötü olması ve komplikasyon oranının yüksek olması nedeniyle 3 alan lenf nodu diseksiyonu rutin olarak önerilmemektedir (32). Japon mide kanseri lenf nodu diseksiyonu siniflamasina göre D1 diseksiyon: perigastrik lenf nodlar1, D2 diseksiyon: D1+ sol gastrik arter, ortak hepatik arter, çölyak ve splenik arter çevresi lenf nodlarını içerir (Şekil 3, Tablo 6). Tip II ve III tümörler için alt mediastinal ve D2 karın lenf nodu diseksiyonu yapılması önerilmektedir (19). Özellikle Japonya kaynaklı çalışmalarda D2 üzerinde abdominal lenf nodu diseksiyonun (paraaortik bölge, retropankreatik bölge, hepatoduodenal ligaman çevresi) anlaml şekilde sağkalıma fayda sağlamadığı gibi postoperatif komplikasyon oranını artırdığı belirtilmiştir $(33,34)$.

Yapılan lenf nodu diseksiyonunun tedaviye katkısını belirlemek için Sasako ve ark'nın (35) geliştirdiği yöntem kullanılmaktadır. Bu yöntemde çalışılan lenf nodu bölgesinin metastaz oranı, o bölgede metastaz tespit edilen hastaların beş yıllık sağkalım oranı ile çarpılarak bir gösterge hesaplanmaktadır. Elde edilen sayının büyüklüğüne göre lenf nodu istasyonunun diseksiyonunun tedavideki yararlılığına karar verilmektedir. Buna göre tip II ve III bileşke tümörleri için özellikle sağ ve sol parakardiyal, küçük kurvatur ve sol gastrik arter kökü lenf nodlarının diseksiyonu en yüksek faydayı sağlamaktadır. İkinci sırada fayda sağlayan lenf nodu grupları ise ortak hepatik arter, çölyak arter, dalak hilusu çevresi, proksimal splenik arter çevresi ve alt torasik paraözofageal lenf nodlarıdır $(23,27,36)$. Rutin paraaortik lenf nodu diseksiyonu önerilmez. (37), Sol renal ven çevresi diseksiyonunun tip II tümörlerde sağkalım avantajı yarattığ1 bildirilmiștir (38). Doğru evreleme için en az 18-23 adet lenf nodu çıkarılması gerektiği bildirilmiştir $(30,39)$.
Morbidite ve mortalite; girişim yolu, rezeksiyon ve lenfadenektomi genișliğine göre değișir. D2 rezeksiyon yap1lirken retroperitoneal lenfadenektomiyi tamamlamak için rutin olarak sol taraf pankreatik rezeksiyon ve splenektomi yapılmasının morbiditeyi artırdığ1 ancak sağkalıma faydasının olmadığ gösterilmiştir (40). Bariz lenf nodu metastazı varlığı ya da splenik hilus tutulumu varlığında splenektomi yapilmas1 gerekiyorsa en azindan pankreas rezeksiyonundan kaçınılmalidir (41).

\section{Tedavi Yaklașımı}

Genel durumu iyi, uzak metastazı olmayan, R0 rezektabl ÖGB adenokarsinomlarında en iyi tedavi cerrahidir (11). 2015 National Comprehensive Cancer Network (NCCN) Kilavuzu'nda lenf nodu metastazı varl1ğında diğer özofagus tümörlerine preoperatif kemoradyasyon tedavisi önerilirken, ÖGB adenokarsinomlarına sadece kemoterapi verilmesi önerilmektedir (42). Preoperatif tedavi sonras1 yapılacak yeniden evreleme sağkalımı belirlemede tedavi öncesi evreye göre daha başarılı gözükmektedir (43). Ayrıca insitu karsinomlara veya sadece mukoza tutulumu olan ÖGB adenokarsinomlarına endoskopik mukozal rezeksiyon öneren yayınlar da mevcuttur (44). Seçilecek cerrahi yöntem konusunda, tip I tümörler için transtorasik fundektomi ve subtotal özofajektomi (İvor Lewis operasyonu), tip III tümörler için genişletilmiş gastrektomi yapılması konusunda literatürde, geniş ölçüde fikir birliği olduğu gözükmektedir (45-48).

Haverkamp ve ark.'nın (49) 2014 yılında 10 kohorttan oluşan derlemelerinde bileşke tümörlerinde özofajektomi ile gastrektomi arasında bariz sağkalım farkı izlenmemesine rağmen, gastrektomi uygulanan hastaların daha iyi yaşam kalitesine sahip oldukları görülmüștür. Ancak tip II tümörler için uygulanacak cerrahi konusunda halen

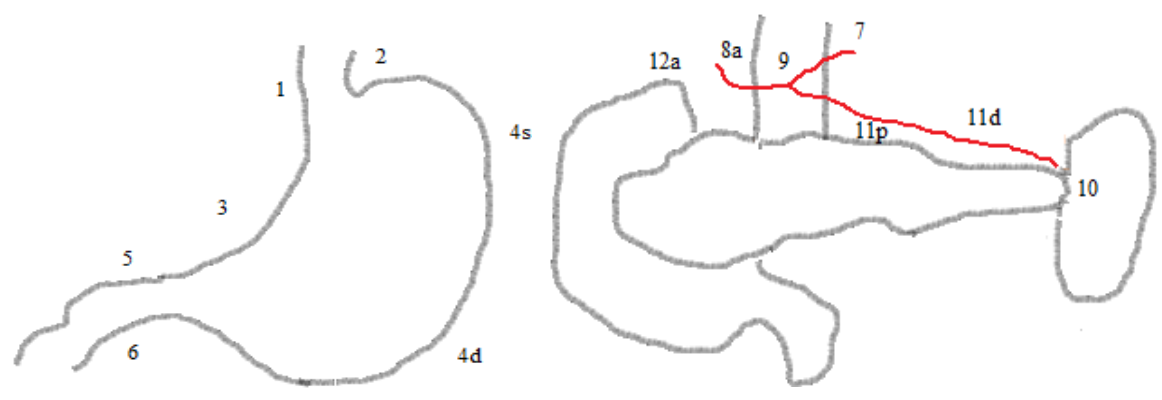

Şekil 3: Japon mide kanseri lenf nodu istasyonları ${ }^{(10)}$

D1 istasyonları: 1, 2, 3, 4s, 4d, 5, 6, 7.

D1+ istasyonları: D1 + 8a, 9, 11p.

$\mathrm{D} 2$ istasyonları: D1 + 8a, 9, 10,11p, 11d, 12a

Tablo 6: Japon mide kanseri lenf nodu istasyonları ve yerleşim yerleri

\begin{tabular}{|l|l|}
\hline LAP istasyon no & Yerleșim Yeri \\
\hline 1 & Sağ parakardiyal nodlar \\
\hline 2 & Sol parakardiyal nodlar \\
\hline 3 & Küçük kurvatur lenf ndoları \\
\hline 4 sa & Kısa gastrik arterler çevresinde sol büyük kurvatur lenf nodları \\
\hline $4 s b$ & Sol gastroepiploik arter boyunca sol büyük kurvatur lenf nodları \\
\hline $4 d$ & Sağ gastroepiploik arter boyunca sağ büyük kurvatur lenf nodları \\
\hline 5 & Suprapilorik lenf nodları \\
\hline 6 & Infrapilorik nodlar \\
\hline 7 & Sol gastrik arter üstü lenf nodları \\
\hline $8 \mathrm{a}$ & Ortak hepatik arter boyunca lenf nodları \\
\hline 9 & Çölyak arter boyunca lenf nodları \\
\hline 10 & Dalak hilusu boyunca lenf nodları \\
\hline $11 \mathrm{p}$ & Proksimal splenik arter boyunca lenf nodları \\
\hline $11 \mathrm{~d}$ & Distal splenik arter boyunca lenf nodları \\
\hline $12 \mathrm{a}$ & Hepatik arter boyunca lenf nodları \\
\hline
\end{tabular}


farklı görüşler bulunmaktadır. Önerilen cerrahi yöntemler abdominal, abdominal-sağ transtorasik, abdominalsol transtorasik, frenotomi ile sol transtorasik, karın-boyun girişim yollarını içermektedir. Rezeksiyon boyutu da sinırlı bileşke rezeksiyonundan total özofagogastrektomiye kadar değişmektedir. Önerilen lenfadenektomi s1nırı da değişkendir (12).

Yayınlanan çalıșmalar ıșığında tip II tümörler için eğer hiatustan tümörün proksimal uzanımı R0 çıkarılabilecekse genişletilmiş gastrektomi yapılması, R0 rezeksiyon yapılamiyacaksa abdominalsağ transtorasik yaklaşımla rezeksiyon uygulanması uygun gözükmektedir (5052). Japonya'dan Mine ve ark.(53) distal tümör uzanımı ile bileșke arasındaki mesafe $5 \mathrm{~cm}$ 'den fazla ise total gastrektomiyi önermektedirler.

Hayat kalitesini temelde seçilen rekonstruksiyon tipi belirlemektedir. Aşağ1 mediastende gerçekleștirilen özofagogastrostomi basit ve güvenli bir yol olmasına rağmen, ciddi gastrik ve duodenal içerik reflüsüne neden olduğu için, dayanılmaz özofajitlere yol açmakta ve hayat kalitesini düşürmektedir. Bu durumdan kaçınmak için özofagogastrik anastomoz yüksek intratorasik (azigoz veni üzeri) veya boyunda yapılabilir. Diğer seçenek özofagus ve anastomoz edilecek mide kısmı arasina jejenum veya kolon getirmektir. Mide fundusu çıkarıldığ 1 ve midenin depolama işlemi ortadan kalktığ için total gastrektomi ve Roux-en-Y anastomozu ile yüksek intratorasik özofagogastrostomi fizyolojik açıdan aynı sonucu verir (54). Fuschs ve ark.'nın (55) 2016 yılında yayınlanan çalışmalarında cerrahi uygulanan 123 bilesske kanserli hastaya postoperatif 2. yillarında hayat kalitesini ölçmek için yapılan anket çalışmasinda total gastrektomi yapılan hastalarda fiziksel işlev, dispne ve reflüye bağlı şikayetlerde özofajektomiye göre anlamlı düşüklük olduğu izlenmiştir.

Transabdominal ve sol torakoabdominal yaklaşımları karşılaştıran çalışmalarda yüksek morbidite ve mortalitesine rağmen sağkalım avantajı sağlamaması nedeniyle sol torakoabdominal yol rutin olarak önerilmemektedir (56).

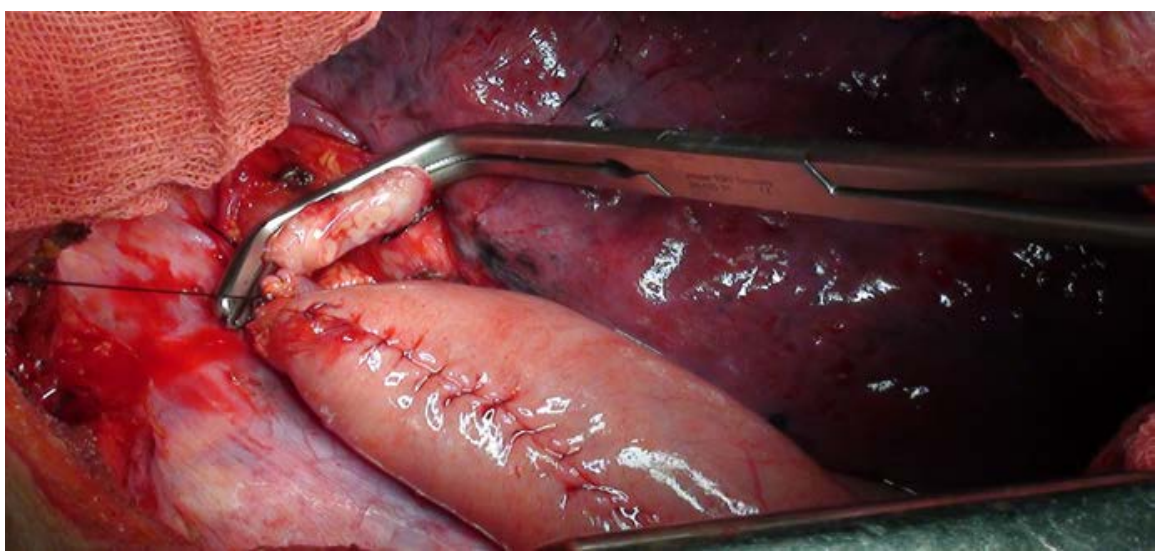

Şekil 4: Laparatomi-sağ torakotomi ile azigos ven düzeyi anastomoz

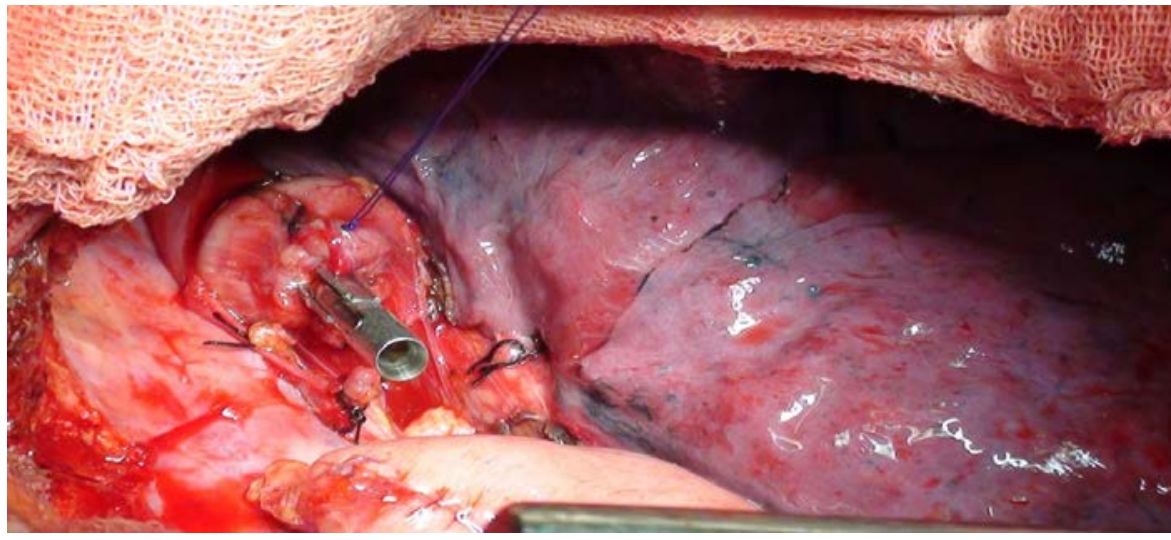

Şekil 5: Sirküler stapler ile anastomoz

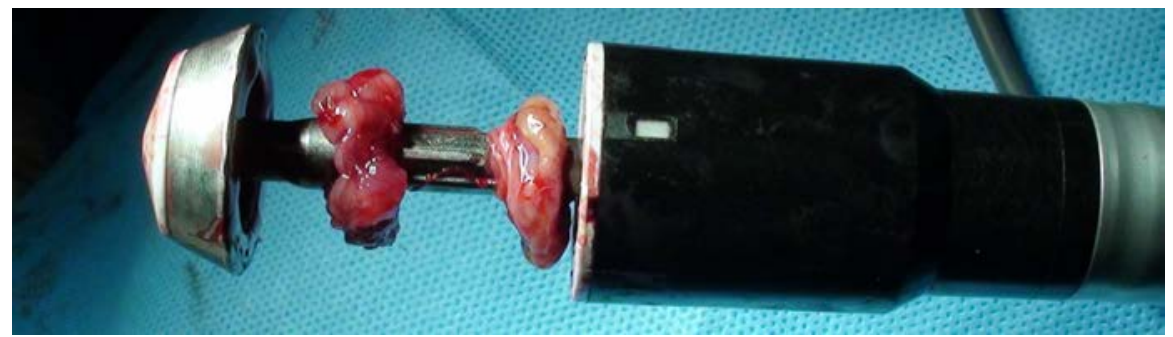

Şekil 6: Özofagus ve mide cerrahi sınırlar

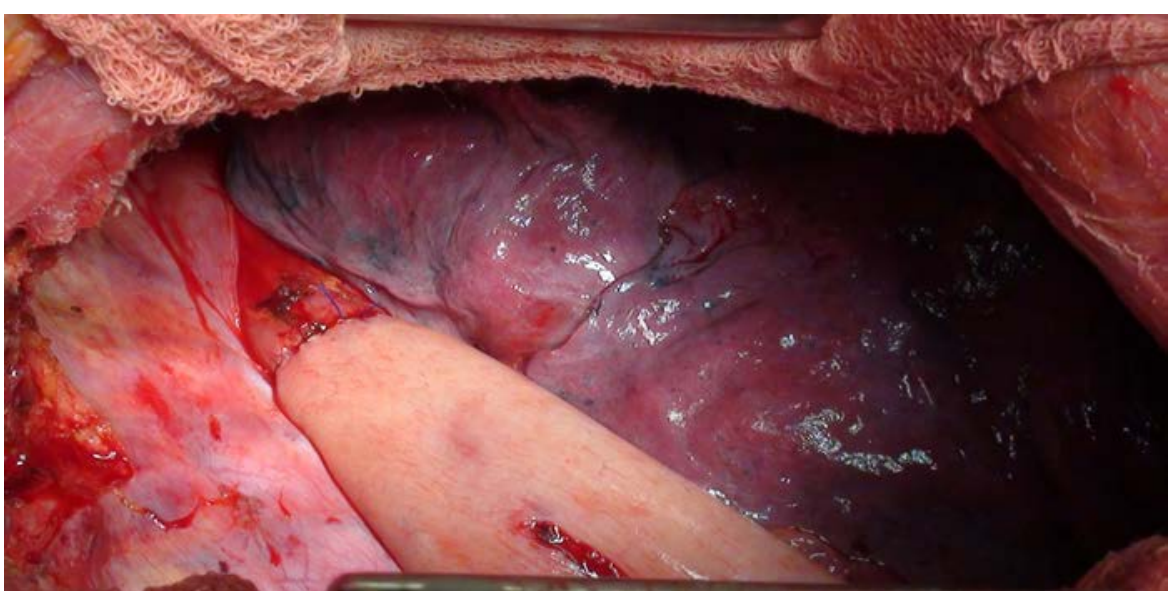

Şekil 7: Anastomoz son hali 
Curtis ve ark'nın (57) 2013 yılında 216 bileşke kanserli hastayı içeren çalışmalarında daha distal tümörlerin daha kötü prognoza sahip oldukları ileri sürülmüștür. Ortanca sağkalım tümör tiplerine göre Tip I:4,9 y1l, Tip II: 3,3 y1l, Tip III: 2,6 yıldır. Bu da postoperatif dönemde takip ve adjuvan tedavi kriterlerini etkileyebilir. Ayrıca Liu ve ark.'nın (58) 2015 yilında yayınlanan Tip II ve III ÖGB ile distal gastrik karsinomları (DGK) karşılaştıran çalışmalarında ÖGB karsinomlu hastaların prognozları DGK'ya göre daha kötü bulunmuştur. Bu bulgu da ÖGB karsinomlarının farklı histopatolojik davranışlarını doğrulamaktadır.

İnratorasik anatomozlarda $\% 10$ civarında izlenen anastomoz kaçakları önemli mortalite sebebi olabilmektedir. Günümüzde erken dönemde yapılan endoskopilerle teşhis edilen kaçaklarda endoskopik stent uygulanabilmekte bu sayede bu komplikasyona bağlı gelişen mortalite ve morbite azalttlabilmektedir (12).

\section{Ivor-Lewis Özofajektomi}

Ivor-Lewis özofajektomi 2 basamaklı bir cerrahi işlem olup, laparatomi ile mide serbestleştirilmesini takiben torakotomi ile özofajektomi ve özoagogastrik anastomozu içerir. Özofagus karsinomlarında, yüksek dereceli displazide, kostik özofageal yaralanmalarda kullanılabilir. Servikal lenf nodu diseksiyonu yapılamamas1, intratorasik anastomozda kaçak meydana gelmesi durumunda sepsis riskinin yüksek olması gibi dezavantajları olsa da, lenf nodu diseksiyonu aç1sindan transhiyatal özofajektomiye üstün olduğu kabul edilir. Özofagogastrik anastomoz sirküler stapler, lineer stapler veya elle anastomoz teknikleri kullanilarak yapılabilir. Atelektazi, anastomoz kaçağ1 veya striktürü, mide boşalmasinda gecikme ve azigos venin altındaki anastomozlarda reflü karşılaşılabilecek potansiyel komplikasyonlardır (59) (Şekil 4-5-6-7-8).

\section{Genișletilmiș Transhiyatal Total Gastrektomi}

Bu operasyonda üst abdomen ve özofagiyal hiatusa erişebilmek kritik önem ta- şımaktadır. Supin pozisyonda torakolomber bölgeye yastık konularak yat1rllan hastaya ters $\mathrm{T}$ şeklinde üst abdomen kesisi uygulanır. Özel bir retraktör yardımı ile sternum kaldırılarak arka mediastene ulaşılmaya çalış1lır. Diyafram hiatustan başlanarak öne doğru açllır. İleri evre tümörlerde diyafragmatik kruslar, her iki mediastinal plevral yaprak distal özofagus ve ÖGB ile birlikte blok halinde çıkarılır. Aşağı arka mediasten, hiatusa konulan özel derin ekartörler yardımı ile trakeal çatallanma bölgesine kadar görülebilir ve bütün lenfatik doku distal özofagus ile birlikte çıkarılabilir. Arkada aorta adventisyasina kadar diseksiyon yapilir. Özofagus tümörün proksimalinden temiz cerrahi sınır bırakılacak şekilde kesilir. Cerrahi sınır tayini için donuk kesit patoloji çalışmak faydalıdır. Ardindan D2 lenfadenektomi ile birlikte total gastrektomi uygulanır. Sonrasında bir sirküler stapler yardımı ile uçyan özofagojejunostomi uygulanır. Duodenuma Roux-en-Y diversiyon uygulanarak operasyon tamamlanır (12) (Şekil 9). Mine ve ark.'nın 2013 y1lında yayınlanan çalıșmalarında transhiyatal gastrektomide $2 \mathrm{~cm}$ 'den daha az proksimal cerrahi sinır birakılmasinın sağkalımı olumsuz yönde etkildiği görülmüştür (60).

Xiao ve ark. (61) 2015 yllında yayınlanan çalışmalarında total gastrektomiye bağlı komorbiditelerden kurtulmak için, standart Roux-en-Y anastomoz yerine antrum koruyucu çift yollu onarımı

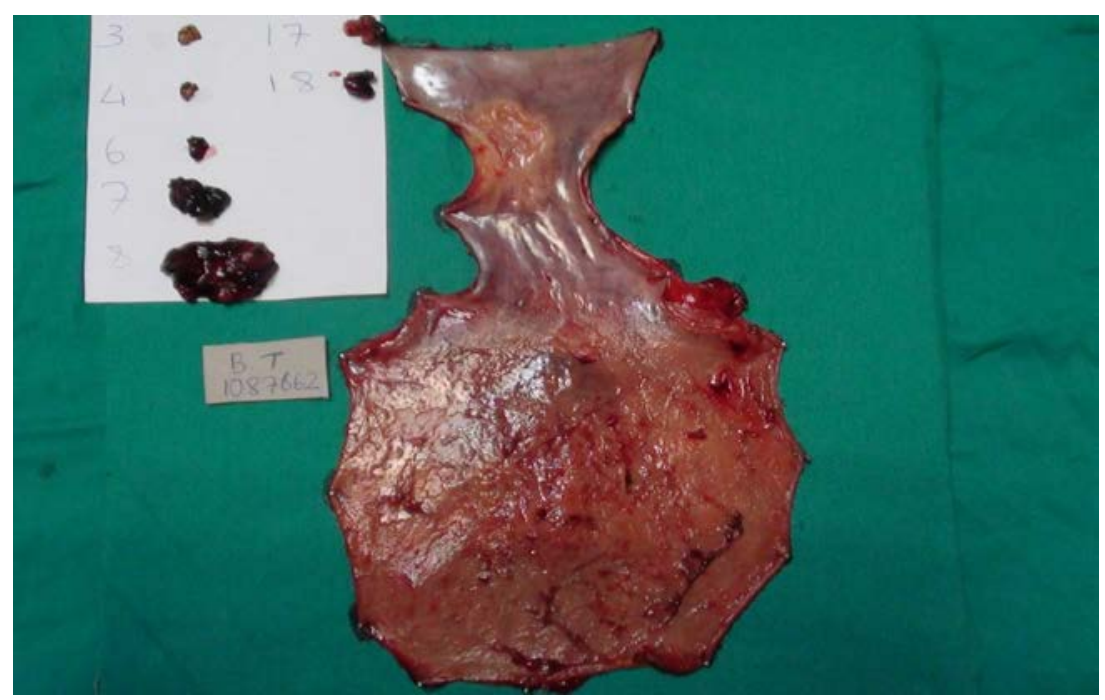

Şekil 8: Tip I tümör patoloji piyesi (Laparotomi-sağ torakotomi ile distal özofajektomi, proksimal gastrektomi, özofagogastrostomi)

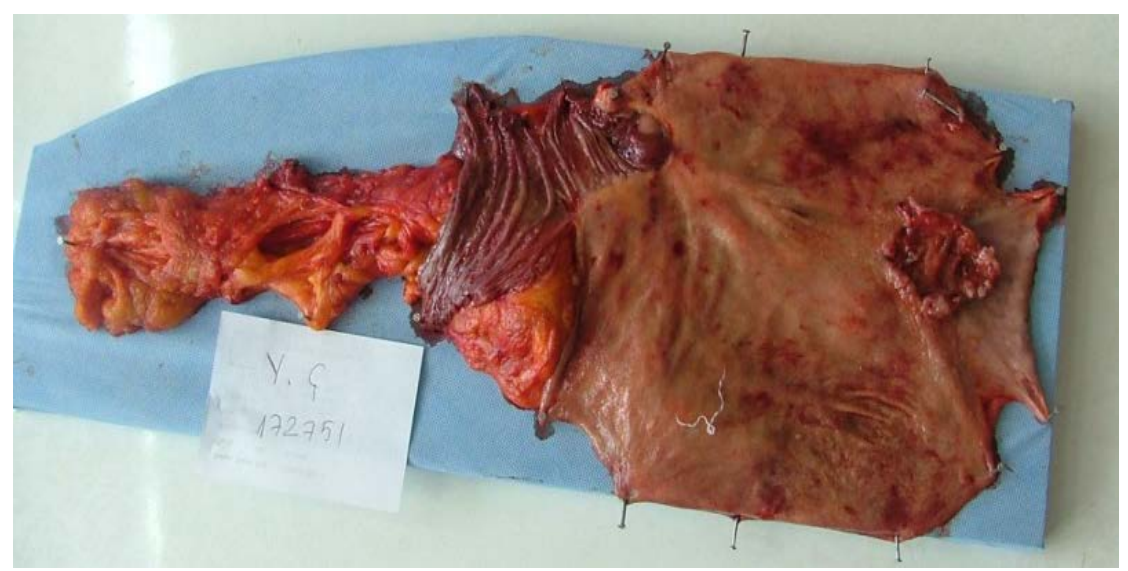

Şekil 9: Tip II tümör (Transhiyatal total gastrektomi, Roux-en-Y özofagojejunostomi) 
önermişlerdir. Bu şekilde benzer sağkalım elde edilirken daha yüksek hayat kalitesi ve daha düşük oranda malnütrisyona bağlı sorunlar izlenmiştir.

\section{Jejunal İnterpozisyonla Sınırlı Rezeksiyon}

Proksimal özofagus total gastrektomide anlatıldığı şekilde lezyonun üzerinden kesilir. Midenin üst 1/3'lük kesimi kesilir. Lenfadenektomi benzer şekilde tamamlanır. Sol gastrik arter çıkış yerinde kesilir ve üzerindeki lenfatik doku ile birlikte spesmende birakilır. Rekonstruksiyon için 15-20 cm uzunluğunda iyi kanlanan güçlü vasküler pediküllü bir jejunal segment, özofagus ve kalan mide proksimali arasına izoperistaltik olarak getirilir. Proksimalde sirküler stapler yardımı ile uç yan özofagojejunostomi, distalde midenin arka duvarına jejunogastrostomi uygulanır (12). Bu teknik genellikle T1N0 tümörler için önerilmektedir.

\section{Endoskopik Yaklașım}

Endoskopik taramaların yaygınlaşması ile günümüzde özofagus kanseri daha erken evrelerde yakalanabilmektedir. Muskularis mukozaya ulaşmayan intramukozal T1a tümörlerde lenf nodu metastaz oranı \%1-3'tür. Bu bilgiler 1şığında iyi diferansiye T1a özofagus adenokarsinomları için endoskopik rezeksiyon ve ablasyon gibi özofagus koruyucu teknikler gündeme gelmiştir. Üçyüz kırkdokuz hastayı içeren prospektif bir çalışmada endoskopik rezeksiyonla $\% 96,6$ oranında tam yanıt elde edilebilmiştir (62).

\section{Sonuç}

Bileşke tümörleri özellikle batı dünyasında s1klığ 1 artan agresif bir malignite grubudur. Bileşke tümörlerinin cerrahi tedavisinde Siewert sinıflaması önemli yer tutmaktadır. Tip I tümörler için transtorasik fundektomi ve subtotal özofajektomi (İvor Lewis operasyonu) ile 2 saha lenfadenektomi, tip III tümörler için genişletilmiş transhiyatal total gastrektomi ile alt medistinal ve D2 karın lenf nodu diseksiyonu yapilması önerilmektedir. Tip II tümörlerde tümörün proksimal uzanımına göre karar vermek gerekmektedir. Eğer $2 \mathrm{~cm}$ güvenli cerrahi sınır bırakılarak tümör çıkarılabilecekse transhiyal total gastrektomi yapılması, çıkar1lamayacaksa transtorasik subtotal özofajektomi eklenmesi önerilmektedir. Erken evre tümörlerde jejunal interpozisyonla sinırlı rezeksiyon ve endoskopik mukozal rezeksiyonlarla başarılı sonuçlar elde edilmiştir.

\section{Teșekkür}

Özel katkılarından dolayı Prof. Dr. Ayten Kayı Cangır'a teşekkür ederiz.

\section{KAYNAKLAR}

1. Buas MF, Vaughan TL. Epidemiology and risk factors for gastroesophageal junction tumors: understanding the rising incidence of this disease. Semin Radiat Oncol 2013;23:3-9.

2. Blot WJ, Devesa SS, Kneller RW, et al. Rising incidence ofadenocarcinoma of the esophagus and gastric cardia. JAMA 1991;265:1287-1289.

3. Hansen S, Wiig JN, Giercksky KE, et al. Esophageal and gastriccarcinoma in Norway 1958-1992: incidence time trend variability according to morphological subtypes and organ subtypes.Int J Cancer 1997;71:340-344.

4. Devesa SS, Blot WJ, Fraumeni JF Jr. Changing patterns in theincidence of esophageal and gastric carcinoma in the United States. Cancer 1998;83:2049-2053.

5. Hasegawa S, Yoshikawa T, Cho H, et al. Is adenocarcinoma of the esophagogastric junction different between Japan and western countries? the incidence and clinicopathological features at a $4258 \mathrm{~S}$. Hasegawa et al. Japanese high-volume cancer center. World J Surg 2009;33:95-103.
6. Ashraf N, Hoffe S, Kim R. Locally Advanced Gastroesophageal Junction Tumor: A Treatment Dilemma. TheOncologist 2015;20:134-142.

7. Kubo A, Corley DA. Body mass index and adenocarcinomas of the esophagus or gastric cardia: a systematic review and meta-analysis. Cancer Epidemiol Biomarkers Prev 2006;15:872-878.

8. Chow WH, Fraumeni JF Jr, Blot WJ et al.Body mass index and risk of adenocarcinomas of the esophagus and gastric cardia. J Natl Cancer Inst 1998;90:150-155

9. Chow WH, Blaser MJ, Blot WJ, et al. An inverse relation between cagA + strains of Helicobacter pylori infection and risk of esophageal and gastric cardia adenocarcinoma. Cancer Res 1998;58:588.

10. Yüksel C, Karabörk A, Ökten İ. Özofagus Kanserinde Helicobacter Pylori ve Barret Özofagus'un Rolü.Ankara Üniversitesi Tıp Fakültesi Mecmuası 2009;62:79-82.

11. Siewert JR, Stein HJ. Classification of adenocarcinoma of the oesophagogastric junction. Br J Surg 1998;85:1457-1459.
12. Siewert JR, Feith M, Stein H. Surgical approach to gastroesophageal junction cancers. In Sugarbaker D, Bueno R, Krasna MJ, ed. Adult Chest Surgery, 1st ed. New York City: McGraw-Hill 2009;109-116.

13. Rice TW, Blacstone EH, Rusch VW. A cancer staging primer: esophagus and esophagogastric junction. J Thorac Cardiovasc Surg 2010;139:527-529.

14. Schröder W, Mönig SP, Baldus SE, et al: Frequency of nodal metastasesto the upper mediastinum in Barrett's cancer. Ann Surg Oncol 2002;9:807-811.

15. Parry K, Haverkamp L, Bruijnen RCG, et al. Surgical Treatment of Adenocarcinomas of the Gastro-esophagealJunction. Ann Surg Oncol 2015;22:597-603.

16. Kakeji Y, Yamamoto M, Ito S, et al. Lymph nodemetastasis from cancer of the esophagogastric junction, and determination of the appropriate nodal dissection. Surg Today 2012;42:351-358.

17. Nunobe S, Ohyama S, Sonoo H, et al: Benefit of mediastinal and paraaorticlymphnode dissection for advanced gastric cancer with esophageal invasion. J Surg Oncol 2008;97:392-395. 
18. Mine S, Sano T, Hiki N, et al. Thoracic lymph node involvement in adenocarcinoma of the esophagogastric junction and lower esophageal squamous cell carcinoma relative to the location of the proximal end of the tumor. Ann Surg Oncol 2014;21:1596-1601.

19. Amenabar A, Hoppo T, Jobe BA. Surgical Management of Gastroesophageal Junction Tumors. Semin Radiat Oncol 2013;23:16-23

20. Xiao WG, Ma K, Peng L, et al. Characteristicsof lymphatic metastasis and surgical approach of adenocarcinoma of the esophagogastric junction. Zhonghua Wei Chang Wai Ke Za Zhi 2012;15:897-900.

21. Hosokawa Y, Kinoshita T, Konishi M, et al.Clinicopathological features and prognostic factors of adenocarcinoma of the esophagogastric junction according to Siewert classification: experiences at a single institution in Japan. Ann Surg Oncol 2012;19:677-683.

22. Fu SJ, Fang WT, Mao T, et al. Comparison ofoutcomes after surgery between adenocarcinoma of the esophagogastric junction and lower thoracic esophagealsquamous cell cancer. Zhonghua Wei Chang Wai Ke Za Zhi 2012;15:893-896.

23. Hasegawa S, Yoshikawa T, Rino Y, et al. Priority of Lymph Node Dissection for Siewert Type II/III Adenocarcinoma of the Esophagogastric Junction. Ann Surg Oncol 2013;20:4252-4259.

24. Kurokawa Y, Sasako M, Doki Y. Treatment Approaches to Esophagogastric Junction Tumors. Dig Surg 2013;30:169173.

25. Okholm C, Svendsen LB, Achiam MP. Status and prognosis of lymph node metastasis in patients with cardia cancer - A systematic review. Surgical Oncology 2014;23:140-146.

26. Yamashita H, Katai H, Morita S, et al. Optimal Extent of Lymph Node Dissection for Siewert Type II Esophagogastric Junction Carcinoma. Annals of Surgery 2011;254:2

27. Goto H, Tokunaga M, Miki Y, et al. The optimal extent of lymph node dissection for adenocarcinoma of the esophagogastric junction differs between Siewert type IIand Siewert type III patients. Gastric Cancer 2015;18:375-381.
28. Pedrazzani C, de Manzoni G, Marrelli D, et al. Lymph node involvement in advanced gastroesophageal junction adenocarcinoma. J Thorac Cardiovasc Surg 2007;134:378-385.

29. Zhang YF, Shi J, Yu HP, et al. Factors predicting survival in patients with proximal gastric carcinoma involving the esophagus. World J Gastroenterol 2012;18:3602-3609.

30. Peyre CG, Hagen JA, DeMeester SR, et al. The number of lymph nodesremoved predicts survival in esophageal cancer: An international study on the impact of extent of surgical resection. Ann Surg 2008;248:549-556.

31. Kurokawa Y, Hiki N, Yoshikawa T, et al. Mediastinal lymph node metastasis and recurrence in adenocarcinoma of theesophagogastric junction. Surgery 2015;157:551-555

32. Lerut T, Nafteux P, Moons J, et al. Threefield lymphadenectomy forcarcinoma of the esophagus and gastroesophageal junction in $174 \mathrm{R} 0$ resections: Impact on staging, disease-free survival, and outcome: A plea for adaptation of TNM classification in upper-half esophageal carcinoma. Ann Surg 2004;240:962-972.

33. Maeta M, Yamashiro H, Saito H, et al. A prospective pilot study ofextended (D3) and superextended para-aortic lymphadenectomy (D4) in patients with T3 or T4 gastric cancer managed by total gastrectomy. Surgery 1999;125:325-331.

34. Bonenkamp JJ, Hermans J, Sasako M, et al. Extended lymph-nodedissection for gastric cancer. N Engl J Med 1999;340: 908-914.

35. Sasako M, McCulloch P, Kinoshita T, et al. New method to evaluate the therapeutic value of lymph node dissection for gastric cancer. Br J Surg 1995;82:346-351.

36. Matsuda T, Takeuchi H, Tsuwano S, et al. Optimal surgicalmanagement for esophagogastric junction carcinoma. Gen Thorac Cardiovasc Surg 2014;62:560-566

37. Sasako M, Sano T, Yamamoto S, et al. D2 lymphadenectomyalone or with para-aortic nodal dissection for gastric cancer. N Engl J Med 2008;359:453-462.

38. Mine S, Sano T, Hiki N, et al. Lymphadenectomy around the left renal vein in Siewert type II adenocarcinoma of the oesophagogastric junction. British Journal of Surgery 2013;100:261-266.
39. Rizk N, Venkatraman E, Park B, et al. The prognostic importance of the number of involved lymph nodes in esophageal cancer: implications for revisions of the American Joint Committee on Cancer staging system. J Thorac Cardiovasc Surg. 2006; 132:1374-1381.

40. Goto H, Tokunaga M, Sugisawa N, et al. Value of splenectomy in patients with Siewert type II adenocarcinoma of the esophagogastric junction. Gastric Cancer 2013;16:590-595.

41. Maruyama K, Sasako M, Kinoshita T, et al. Pancreas-preserving total gastrectomy for proximal gastric cancer. World J Surg 1995;19:532-536.

42. Ajani JA, D'Amico TA, Almhanna K, et al. Esophageal and Esophagogastric Junction Cancers, Version 1.2015. JNCCN-Journal of the National Comprehensive Cancer Network, Volume 13 Number 2, February 2015.

43. Davies AR, Gossage JA, Zylstra J, et al. Tumor Stage After Neoadjuvant Chemotherapy Determines Survival After Surgery for Adenocarcinoma of theEsophagus and Esophagogastric Junction. J Clin Oncol 2014;32:2983-2990.

44. Imai K, Kakushima N, Tanaka M, et al. Validation of the application of the Japanese curative criteria for superficial adenocarcinoma at the esophagogastric junction treated by endoscopic submucosal dissection: a long-term analysis. SurgEndosc 2013;27:2436-2445

45. Siewert JR, Stein HJ, Feith M. Adenocarcinoma of the esophago-gastricjunction. Scand J Surg 2006;95:260-269.

46. Siewert JR, Feith M, Werner M, et al. Adenocarcinoma of the esophagogastric junction: Results of surgical therapy based on anatomical/topographic classification in 1,002 consecutive patients. Ann Surg 2000;232:353-361

47. Gertler R, Stein HJ, Langer R, et al. Longterm outcome of 2920 patients with cancers of the esophagus and esophagogastric junction: Evaluation of the New Union Internationale Contre le Cancer/American Joint Cancer Committee staging system. Ann Surg 2011;253:689-698.

48. von Rahden BH, Stein HJ, Siewert JR: Surgical management of esophagogastric junction tumors. World J Gastroenterol 2006;12:6608-6613 
49. Haverkamp L, Ruurda JP, van Leeuwen MS, et al. Systematic review of the surgical strategies of adenocarcinomas of the gastroesophageal junction. Surgical Oncology 2014;23:222-228.

50. Hulscher JBF, van Sandick JW, de Boer AG, et al. Extended transthoracic resection compared with limited transhiatal resection for adenocarcinoma of the esophagus. N Engl J Med 2002;347:1662-1669.

51. Feith M, Stein HJ, Siewert JR. Adenocarcinoma of the esophagogastric junction: Surgical therapy based on 1602 consecutive resected patients.Surg Oncol Clin N Am 2006;15:751-764.

52. Omloo JM, Lagarde SM, Hulscher JB, et al: Extended transthoracic resection compared with limited transhiatal resection for adenocarcinoma of the mid/distal esophagus: Five-year survival of a randomized clinical trial. Ann Surg 2007;246:992-1000.

53. Mine S, Kurokawa Y, Takeuchi $\mathrm{H}$, et al. Distribution of involved abdominal lymph nodes is correlated with the distance from the esophagogastric junction to the distal end of the tumor in Siewert type II tumors. EJSO 2015;41:1348-1353.
54. Stein HJ, Feith M, Siewert JR: Individualized surgical strategies for cancer of the esophagogastric junction. Ann Chir Gynaecol 2000;89:191-198.

55. Fuchs H, Hölscher AH, Leers J, et al Long-term quality of life after surgery for adenocarcinoma of the esophagogastric junction: extended gastrectomy or transthoracic esophagectomy? Gastric Cancer 2016;19:312-317.

56. Sasako M, Sano T, Yamamoto S, et al. Left thoracoabdominal approach versus abdominal-transhiatal approach for gastric cancer of the cardia or subcardia: a randomized controlled trial. Lancet Oncol 2006;7:644-651.

57. Curtis NJ, Noble F, Barley IS, et al. The Relevance of the Siewert Classification in the Era of Multimodal Therapy for Adenocarcinoma of the Gastro-Oesophageal Junction. Journal of Surgical Oncology 2014;109:202-207.

58. Liu K, Zhang W, Chen X, et al. Comparison on Clinicopathological Features and Prognosis Between Esophagogastric Junctional Adenocarcinoma (Siewert II/III Types) and Distal Gastric Adenocarcinoma: Retrospective Cohort Study, a
Single Institution, High Volume Experience in China. Medicine. 2015;94: e1386.

59. Kocaman G, Enön S. Ivor-Lew1s Özofajektomi. Erişim tarihi: 26.05.2016, http:// www.toraks.org.tr/Download.aspx?book $=1474$

60. Mine S, Sano T, Hiki N, et al. Proximal margin length with transhiatal gastrectomy for Siewert type II and III adenocarcinomas of the oesophagogastric junction. British Journal of Surgery2013;100:10501054.

61. Xiao JW, Liu ZL, Ye PC, et al. Clinical comparison of antrum-preserving double tract reconstruction vs roux-en-Y reconstruction after gastrectomy for Siewert types IIand IIIadenocarcinoma of the esophagogastric junction. World J Gastroenterol2015;21:9999-10007.

62. Pech O, Behrens A, May A, et al: Longterm results and risk factor analysis for recurrence after curative endoscopic therapy in 349 patients with high-grade intraepithelial neoplasia and mucosal adenocarcinoma in Barrett's oesophagus. Gut 2008;57:1200-1206. 
